\title{
Camera-Based Monitoring of Neck Movements for Cervical Rehabilitation Mobile Applications
}

\author{
Iosune Salinas-Bueno ${ }^{1}$, Maria Francesca Roig-Maimó ${ }^{2, *}$, Pau Martínez-Bueso ${ }^{1}$, Katia San-Sebastián-Fernández ${ }^{3}$, \\ Javier Varona ${ }^{2}$ and Ramon Mas-Sansó ${ }^{2}$ \\ 1 Department of Nursing and Physiotherapy, University of the Balearic Islands, Health Research Institute of the \\ Balearic Islands (IdISBa), 07122 Palma, Spain; iosune.salinas@uib.es (I.S.-B.); paz.martinez@uib.es (P.M.-B.) \\ 2 Department of Mathematics and Computer Science, University of the Balearic Islands, 07122 Palma, Spain; \\ xavi.varona@uib.es (J.V.); ramon.mas@uib.es (R.M.-S.) \\ 3 Department of Nursing and Physiotherapy, University of the Balearic Islands, 07122 Palma, Spain; \\ katia.sansebastian@uib.es \\ * Correspondence: xisca.roig@uib.es
}

check for

updates

Citation: Salinas-Bueno, I.;

Roig-Maimó, M.F.;

Martínez-Bueso, P.;

San-Sebastián-Fernández, K.;

Varona, J.; Mas-Sansó, R.

Camera-Based Monitoring of Neck

Movements for Cervical

Rehabilitation Mobile Applications.

Sensors 2021, 21, 2237. https://

doi.org/10.3390/s21062237

Academic Editor: Bert Arnrich

Received: 30 January 2021

Accepted: 19 March 2021

Published: 23 March 2021

Publisher's Note: MDPI stays neutral with regard to jurisdictional claims in published maps and institutional affiliations.

Copyright: (c) 2021 by the authors. Licensee MDPI, Basel, Switzerland. This article is an open access article distributed under the terms and conditions of the Creative Commons Attribution (CC BY) license (https:// creativecommons.org/licenses/by/ $4.0 /$ )

\begin{abstract}
Vision-based interfaces are used for monitoring human motion. In particular, camera-based head-trackers interpret the movement of the user's head for interacting with devices. Neck pain is one of the most important musculoskeletal conditions in prevalence and years lived with disability. A common treatment is therapeutic exercise, which requires high motivation and adherence to treatment. In this work, we conduct an exploratory experiment to validate the use of a non-invasive camera-based head-tracker monitoring neck movements. We do it by means of an exergame for performing the rehabilitation exercises using a mobile device. The experiments performed in order to explore its feasibility were: (1) validate neck's range of motion (ROM) that the camera-based head-tracker was able to detect; (2) ensure safety application in terms of neck ROM solicitation by the mobile application. Results not only confirmed safety, in terms of ROM requirements for different preset patient profiles, according with the safety parameters previously established, but also determined the effectiveness of the camera-based head-tracker to monitor the neck movements for rehabilitation purposes.
\end{abstract}

Keywords: camera-based; inertial sensors; neck; cervical rehabilitation; serious game; head-tracker; therapeutic exercise

\section{Introduction}

Camera-based interfaces provide a hands-free approach to interact with devices. Therefore, they have a straight application in assistive tools for motor-impaired users [1] but also for rehabilitation purposes [2]. Specifically, head-trackers vision-based interfaces, a camera-based approach that tracks the motion of the head, could be used for neck rehabilitation purposes as they demand the movement of the neck joints to interact with the device.

Neck pain is one of the most important musculoskeletal conditions in prevalence and years lived with disability, as it becomes chronic in $30-50 \%$ of cases $[3,4]$. The common treatment of neck pain includes conservative and pharmacological interventions. Conservative treatments often include therapeutic exercise, with the aim of improve mobility, pain, function and quality of life [5-7]. Therapeutic exercise, usually supervised by a physiotherapist, includes mobility, strengthening, endurance and motor control exercises $[5,7,8]$. The long-term beneficial effect is achieved by performing the therapeutic exercise constantly and over time, which requires high motivation and adherence to treatment, especially when it is done at home. The adherence to the treatment will therefore be essential for the maintenance of the effects [5]. One potential way to increase adherence is by means of an exergame, that is, a serious game that aims at physical exercise (in our case, neck 
therapeutic exercise) while entertaining the user. The exergame allows therapeutic exercise performance with assets of motivation, supervision and feedback, which are key factors of adherence $[9,10]$.

With that aim, we started the design and development of a specific mobile application that monitors and analyses the fulfilment of neck therapeutic exercises at home (or elsewhere). The application includes an exergame individually adapted to the user capabilities at any time of the rehabilitation process. By means of a camera-based head-tracker, user head motion is detected, and used to interact with the exergame application in order to monitor that users perform correctly the neck movements. The use of the camera has the advantage that it is not invasive, and the user can move comfortably without external limitations. In addition, the fact that it is a mobile application allows doing the therapeutic exercise, with supervision and feedback, available everywhere, anytime, and to anyone.

This paper presents the validation experiments performed in order to (1) explore the feasibility of using the head-tracker interface for neck rehabilitation purposes, in the sense of the range of motion (ROM) that the head-tracker was able to detect and (2) determine the safety of the application, as an exploratory safety experiment, in terms of neck ROM solicitation by the mobile application.

\subsection{State-of-the-Art}

It has been proved in the literature that introducing gamification to therapeutic exercise in rehabilitation increases its effectiveness and adherence [11-14]. In this sense, serious exergames have been explored for different rehabilitation purposes, both using commercial games and devices in a rehabilitation context [15] or designing specific serious exergames for health and rehabilitation purposes, under more specific and clinical criteria design [11-14]. Serious exergames have proved to be effective in different neurological and musculoskeletal diseases [12,16,17]. In recent years, several virtual reality (VR) (immersive and non-immersive) serious games for rehabilitation have been developed [16-19]. If they were specifically aimed to a body part, they needed to attach a wearable sensor to the part of the body, as happened in the work of De Oliveira et al. [17], Rechy-Ramirez et al. [20] or interact with a full body camera detection [21]. With the aim of using serious gaming with smartphones or mobile devices, with integrated sensors on the mobile phone, Baranyi et al. [16,22] are developing a serious game system for post-stroke rehabilitation. Regarding specifically neck region, Mihajlovic et al. [23] developed a virtual reality serious game, but in order to create the immersion on VR a headset needed to be used by the patient. As for neck movements detection with mobile devices, there have been some authors that have developed neck exercise systems with sensors integrated in mobile devices, i.e., with camera-based head tracking. Lawanont et al. [24,25] developed a neck movement image detection integrated in the smartphone sensors. It was able to calculate neck flexion, so it fulfilled the purpose of monitoring head posture while using smartphones. Yet, it did not detect or monitor other directions of movement. Thus, the issue of detecting all directions on neck movements with no sensors on the user, and to use them as an interaction for a serious exergame for neck rehabilitation with a mobile device remains to explore.

\subsection{Camera-Based Head Tracking}

One common sensor on smartphones and tablets is the front-facing camera, that can be used to perform the user's head tracking. Such camera-based head-trackers provide a way to interact with these devices through the movements of the head. Using a visionbased head-tracker has several advantages. Mainly, it does not require any calibration or additional hardware, apart from the components already built in mobile devices. It also has the additional advantage that it is not invasive, i.e., the user can comfortably move without the burden imposed by wires or markers. The only requirement is that the main structures of the face (eyes and nose) have to be fully visible by the front-facing camera.

We have previously developed a camera-based head-tracker for mobile devices [26] that automatically detects and tracks the position of the user's nose. To track the nose, 
the system extracts facial features of its surrounding region, and returns the average of all these features as the nose point. As this region is never occluded by facial hair or glasses, it can be continuously tracked despite the orientation of the user's head when he or she is looking at the screen. We direct the reader to Roig-Maimó et al. [26] for a technical description of the head-tracker interface.

Previous work validated the head-tracker's viability as a pointing device in targetselection tasks with able-bodied [27] and motor-impaired users [28]. Once the head-tracker interface was validated from the point of view of Human-Computer Interaction, in this work we analyse the feasibility of using it to develop applications for cervical rehabilitation purposes, as it allows the interaction with devices through the movement of the head.

\section{Exploratory Experiment: Neck Range of Motion Tracked by the Camera-Based Head-Tracker}

An exploratory experiment was conducted in order to explore the neck ROM that is effectively tracked by the camera-based head-tracker. With this experiment, we wanted to determine at what extent the head-tracker was able to track the mobility range of the neck, in order to determine if it could be used for ROM rehabilitation purposes.

The cervical area has a normal maximum mobility of $45^{\circ}$ of flexion, $45^{\circ}$ of extension, $45^{\circ}$ of lateral flexion (each side) and $70^{\circ}$ of rotation (each side) [29]. See Figure 1 in order to observe the movements of the neck joint. Functional mobility, understood as the range of motion used in daily life activities, is $20 \%$ to $40 \%$ of maximum available cervical ROM [30,31]. Any kind of change in those ROM would alter the functional mobility of the neck and spine, which could alter also the functionality of individuals, causing disability movement $[32,33]$.

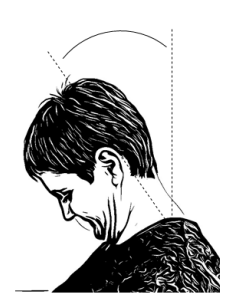

Flexion

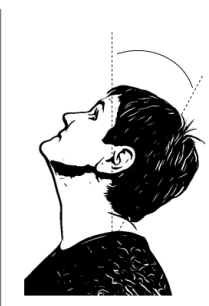

Extension

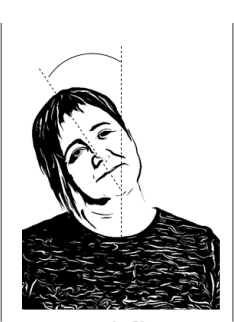

Lateral flexion

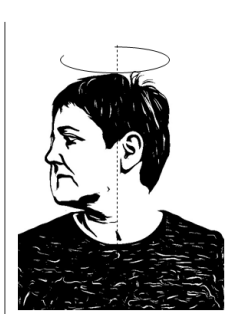

Rotation

Figure 1. Movements of the neck.

Seven participants (six females) were recruited from a university campus in Spain. They were staff from the university campus who volunteered for the experiment. Ages ranged from 29 to 48 with a mean of 39.14 years $(S D=6.76)$. There were no requirements or exclusion criteria on prior experience to participate in the experiment.

The experiment was conducted on an Apple iPad Air with a front-facing camera placed in the center on the upper side of the device, in portrait orientation. The software executed the head-tracker interface and showed on the screen the image captured by the front-facing camera with the nose point returned by the head-tracker marked with a blue circle (see Figure 2).

An important added value of using the exergame is to enable the user to perform the exercises alone by means of controlling the correct performance. Therefore, it is very important to consider the system's feedback to inform the user and to help him or her to control the performance. In this sense, it is necessary to explore the neck range of motion (ROM) that could be effectively tracked by the camera-based head-tracker, as a feasibility indicator for neck rehabilitation purposes. 


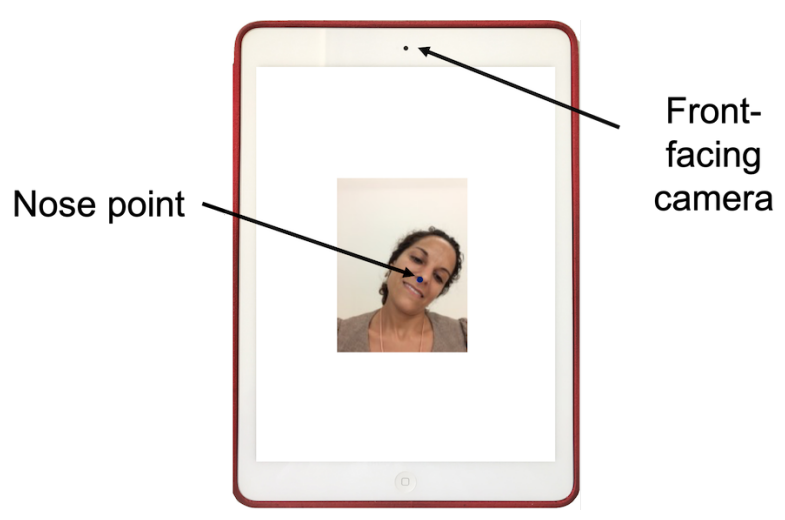

Figure 2. Screenshot of the experiment software with annotations on an Apple iPad Air (device in portrait orientation).

Each participant performed the session in an experiment room, seated in upright position, resting their arms on a table. The iPad with the camera-based head-tracker running, was placed in front of their face at approximately $37 \mathrm{~cm}$, a distance equivalent to naturally holding the device by the subject, with the top line of the iPad screen at eye level [34].

They were asked to move their head slowly as far as possible in the direction being studied (flexion, extension, right lateral flexion, left lateral flexion, right rotation and left rotation). See Figure 3. At the moment that the head-tracker lost the position of the nose (see Figure 3c), an acoustic alert sounded and the participant was asked to stop the movement. Then, ROM was measured with a goniometer (see Figure 4c), that is a reliable tool for ROM measurement used in standardized clinical examinations [35-37]. It consisted of a stationary arm, a movable arm and a fulcrum or axis, as can be seen in Figure 5.

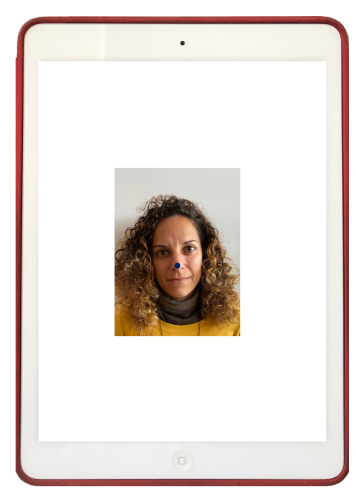

(a)

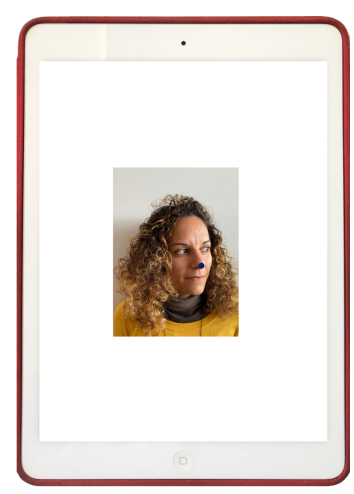

(b)

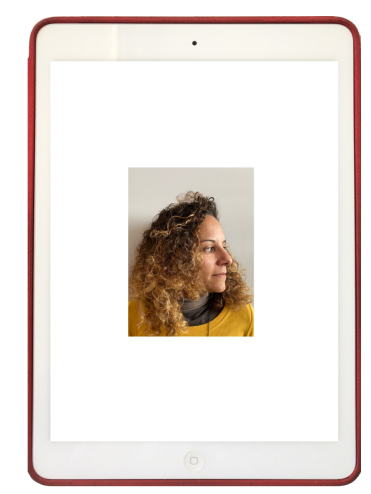

(c)

Figure 3. Simulated stages of the experiment procedure for the left rotation movement on the apparatus: (a) participant placed in the initial position with the nose point returned by the headtracker marked with a blue circle, (b) the participant starts a rotation movement slowly (the nose point returned by the head-tracker is marked with a blue circle), (c) moment when the head-tracker loses the position of the nose (an acoustic alert is triggered) and the participant stops its movement.

Flexion and extension were measured with the axis over the external auditory meatus, with the stationary arm parallel to ground and the movement arm in line with the base of nares. Lateral flexion was measured with the axis over spinous process of C7 vertebra, with the stationary arm in line with spinous processes of thoracic vertebrae, so that arm was perpendicular to ground, and the movement arm in line with occipital protuberance. Rotation was measured with the axis located over central aspect of head, with the stationary arm parallel to imaginary line between the two acromial processes, and the movement arm in line with the tip of the nose. All measurements were conducted by an experienced physiotherapist. 


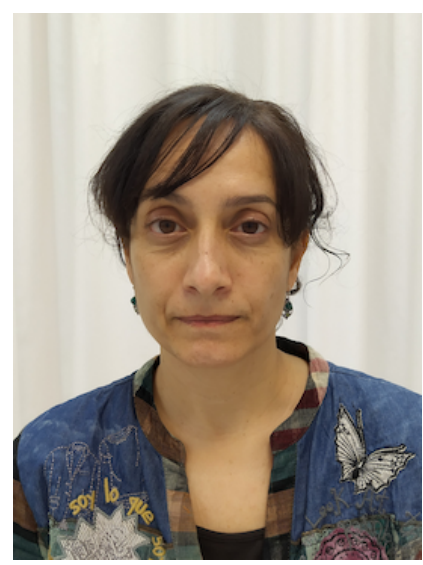

(a)

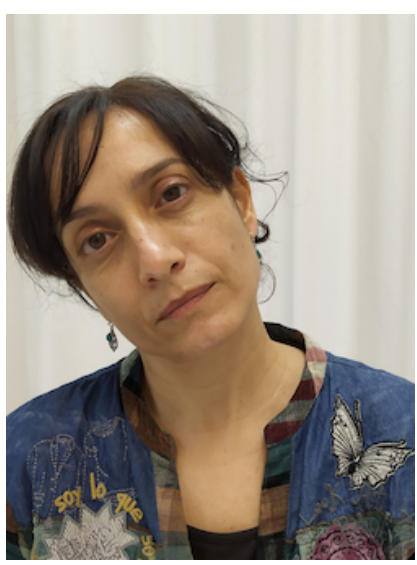

(b)

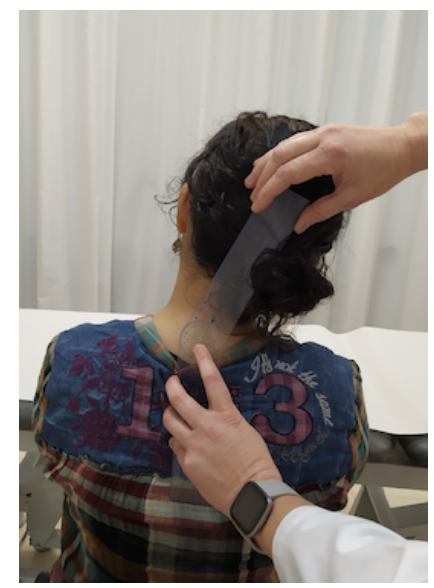

(c)

Figure 4. Stages of the experiment procedure: (a) participant placed in the initial position, (b) participant once the acoustic alert sounded and the participant stopped the movement, (c) measurement of the neck ROM of the participant using the goniometer.

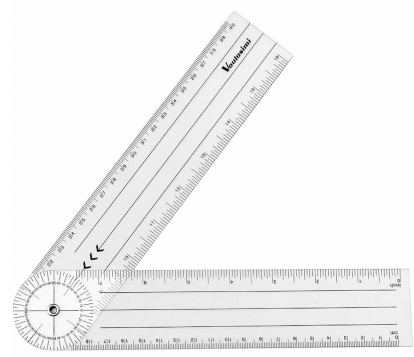

Figure 5. Dual-arm universal goniometer.

Each movement was repeated three times, and equally measured (see Figure 4). Testing lasted about 15 min per participant.

The total number of measures was 7 participants $\times 6$ directions $\times 3$ repetitions $=126$.

In Table 1, mean and standard deviation values, as well as proportion of normal maximum ROM tracked, are given for each movement direction of the cervical area (flexion, extension, right lateral flexion, left lateral flexion, right rotation, left rotation).

Table 1. Mean values and standard deviation of cervical range of motion measurements, and their relationship with normal mobility range.

\begin{tabular}{cccc}
\hline Movement & ROM Detected & Normal Maximum ROM & \% of Maximum ROM Tracked \\
\hline Flexion & $29.05^{\circ} \pm 6.25^{\circ}$ & $45^{\circ}$ & $64.55 \%$ \\
Extension & $22.86^{\circ} \pm 6.63^{\circ}$ & $45^{\circ}$ & $50.79 \%$ \\
Right lateral flexion & $27.39^{\circ} \pm 4.64^{\circ}$ & $45^{\circ}$ & $60.85 \%$ \\
Left lateral flexion & $28.10^{\circ} \pm 3.70^{\circ}$ & $45^{\circ}$ & $62.43 \%$ \\
Right rotation & $39.05^{\circ} \pm 6.25^{\circ}$ & $70^{\circ}$ & $55.78 \%$ \\
Left rotation & $38.81^{\circ} \pm 6.70^{\circ}$ & $70^{\circ}$ & $55.44 \%$ \\
\hline
\end{tabular}

As it is shown in Table 1 and Figure 6, the camera-based head-tracker was able to track the nose position from $50 \%$ to $64.5 \%$ of the normal maximum cervical mobility ranges. The better detected movements were flexion and lateral flexion, that is, the movements where nose is more visible for the front-facing camera during the user's movement. Extension implies that nose would be seen in a different position as movement advances, so 
the head-tracker would lose the nose position at about $23^{\circ}$ of extension. As for rotation, the head-tracker was able to track the nose position up to about $40^{\circ}$, moment where the nose was no longer visible from the front by the front-facing camera.

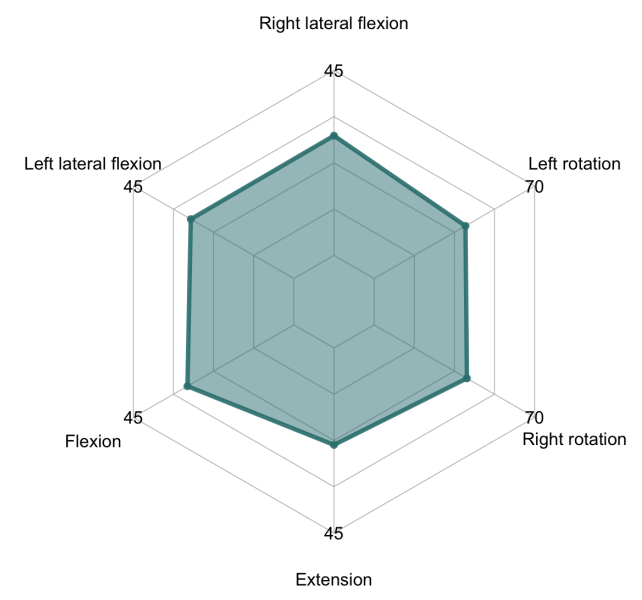

Figure 6. Mean values of the neck range of motion (ROM) tracked by the head-tracker interface compared to normal maximum mobility.

These results proved that the camera-based head-tracker could track the nose position within functional ROM limits, so it could be useful for the rehabilitation of functional mobility, as well as other parameters of rehabilitation (speed of movement, motor control, oculocervical dissociation) within these ranges. This conclusion led us to the design of a mobile application with an exergame that would aim to rehabilitation of functional movement and motor control.

\section{Validation of the Mobile Application for Monitoring the Neck Movements}

Once it was proved that the camera-based head-tracker was feasible for rehabilitation purposes, in the matter of monitoring functional mobility, the application started to be designed. One of the first steps was to determine its safety, in terms that the software must not require more ROM, rapid or complex movements than patients were able to perform at that moment, as they could cause harm and be counterproductive for patients' recovery. Therefore, a safety validation was needed.

\subsection{Materials and Methods}

For this first safety experiment we focused on the ROM that the software required, because demanding more movement that a patient was able to perform, or a movement that reproduced pain, was considered a potential source of unsafe situations. We would consider the application as safe, in this sense, if the movements asked for the application and therefore performed by the subject in each direction were within the maximum ROM that a patient was able to achieve with no pain. As it was expected to be safe for different patients with different capabilities, or the same patient at different moments of his or her recovery, it was considered necessary to study safety with different capability profiles.

In order to do that, different patient preset profiles were designed. They were designed by experienced physiotherapists, based on general clinical evolution of ROM and neck pain data in actual patients [38,39]:

- Profile 1: corresponded to a low cervical mobility person with or without pain associated with movement.

- Profile 2: corresponded to a lower-medium cervical mobility person, with less or no pain associated with movement.

- Profile 3: corresponded to an upper-medium mobility person and no pain. 
- Profile 4: was supposed to represent a patient with an advanced recovery situation or a healthy subject, with normal mobility and no pain.

Range of motion preset for each profile can be seen in Table 2 .

Table 2. ROM of the preset profiles.

\begin{tabular}{ccccc}
\hline Profile & Flexion & Extension & Lateral Flexion & Rotation \\
\hline Profile 1 & $20^{\circ}$ & $15^{\circ}$ & $5^{\circ}$ & $25^{\circ}$ \\
Profile 2 & $30^{\circ}$ & $20^{\circ}$ & $35^{\circ}$ & $40^{\circ}$ \\
Profile 3 & $40^{\circ}$ & $40^{\circ}$ & $45^{\circ}$ & $70^{\circ}$ \\
Profile 4 & $45^{\circ}$ & $45^{\circ}$ & $45^{\circ}$ & $70^{\circ}$ \\
\hline
\end{tabular}

We designed an exergame simulating a dart game with targets to be selected using the movement of the head (see Section 3.1.2 for further description of the game). The configuration of target size, target location, order of targets, time of appearance and disappearance of the target, gain of the head-tracker and dwell-time criterion for selection were set differently for each preset profile:

- Profile 1: required horizontal, vertical or diagonal simple movements with low ROM, with no speed or time pressure. So, configuration for this profile consisted in offering big, easy targets available all the time, that should be selected in a predetermined order, with a high gain factor and no dwell-time. As an example, to require a simple right rotation movement, three big targets available at the same time, that should be selected left to right, were shown on the screen (see Figure 7a).

- Profile 2: the group of exercises included for this profile were those for profile 1 plus exercises with smaller targets, complex movements, and higher speed. These exercises configuration implied more and smaller targets, and a sequential appearance and disappearance of targets, in the preset order of selection, as to introduce a speed factor. As examples of these exercises, Figure $7 \mathrm{~b}$ shows the location of targets in a simple flexion movement, starting with the upper target, and Figure $7 \mathrm{c}$ shows a combined movement: a diagonal.

- Profile 3: the group of exercises loaded for this profile were those with smaller targets, complex movements, movements at a higher speed and motor control requirements. To do so, targets would appear in a random location, with preset time of appearance and disappearance, and with dwell-time to require steadiness in target selection (see an example exercise in Figure 7d).

- Profile 4: the group of exercises loaded for this profile were provided with small targets, complex randomly required movements at a high speed, and motor control requirements. It did not imply more ROM than the previous profiles, as it focused in other parameters (speed, reaction time, motor control). The configuration was similar to profile 3 exercises, but with smaller targets, less time available on screen, less gain factor and more dwell-time on those with motor control requirement.

For the application to be considered as safe, it was supposed to solicit movements within the maximum ROM preset for each profile (see Table 2). In order to validate that the application induced the user to correctly perform the neck movements for every preset profile, it was required that the performed user neck movements were within 80th percentile of the ROM preset for each movement in the different profiles. 


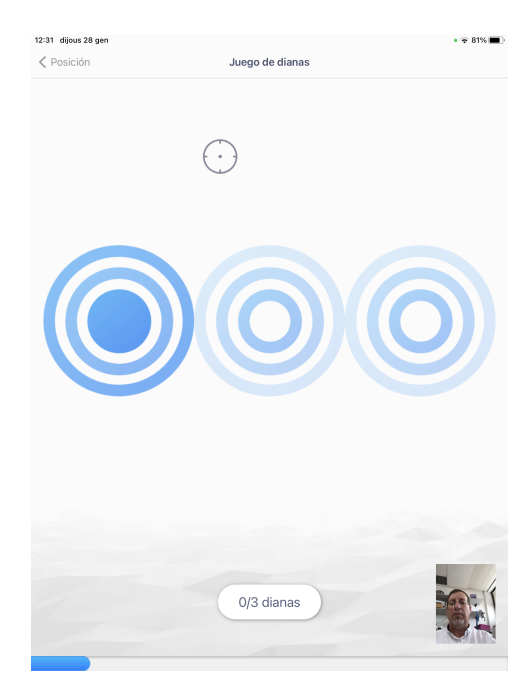

(a)

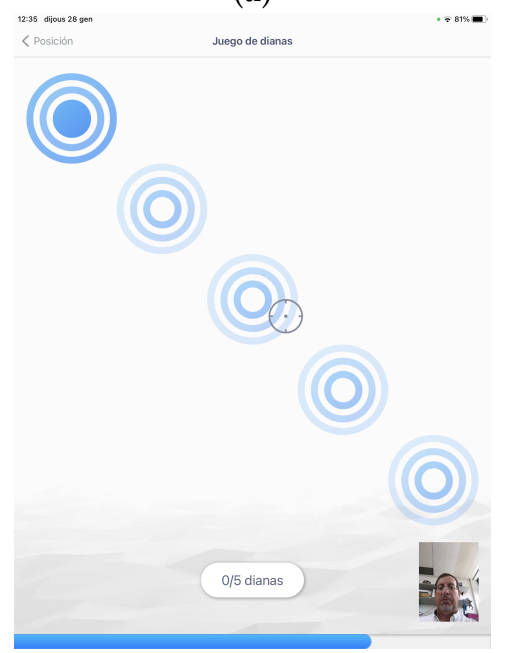

(c)

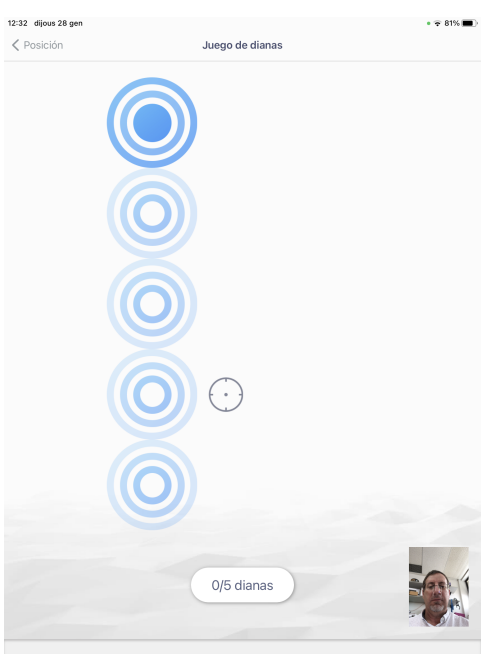

(b)

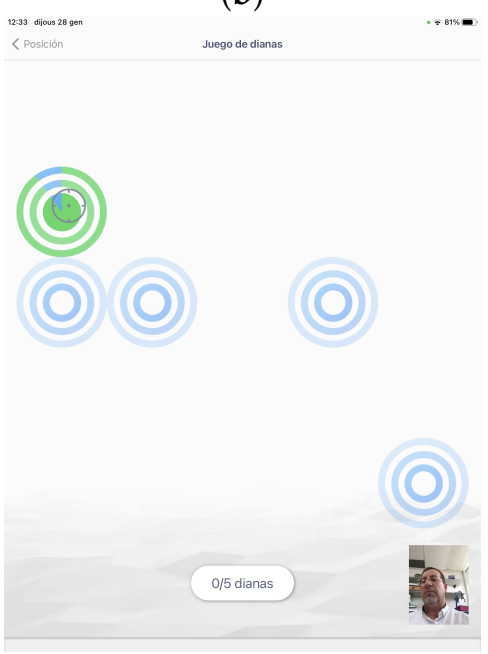

(d)

Figure 7. Examples of exercises for every preset profile: (a) dartboards set to induce a simple horizontal movement (rotation) with big targets, (b) dartboards set to induce a simple vertical descending movement (flexion) with small targets, (c) dartboards set in diagonal to induce a combined movement with small targets, and (d) dartboards set randomly.

\subsubsection{Participants}

A total of 24 asymptomatic participants (12 females) were recruited from staff and postgraduate students from a university campus in Spain. To be included, participants had to be aged 20 to 64 . The average age was 34 years $(S D=13.06)$. They were excluded if they had reported or complained of neck, shoulder, and/or head impairments or had pain in the preceding month.

\subsubsection{Apparatus}

The experiment was conducted on an Apple iPad Mini 4 due to ergonomic reasons related to the device's weight. All communication with the mobile device was disabled during testing.

The software simulated a dart game (see Figure 8 for details). The study involved a simple pointing task where the targets to be selected simulated dartboards of different sizes. User input combined the mobile head-tracker for the pointing action and a dwell-time criterion for selection. 


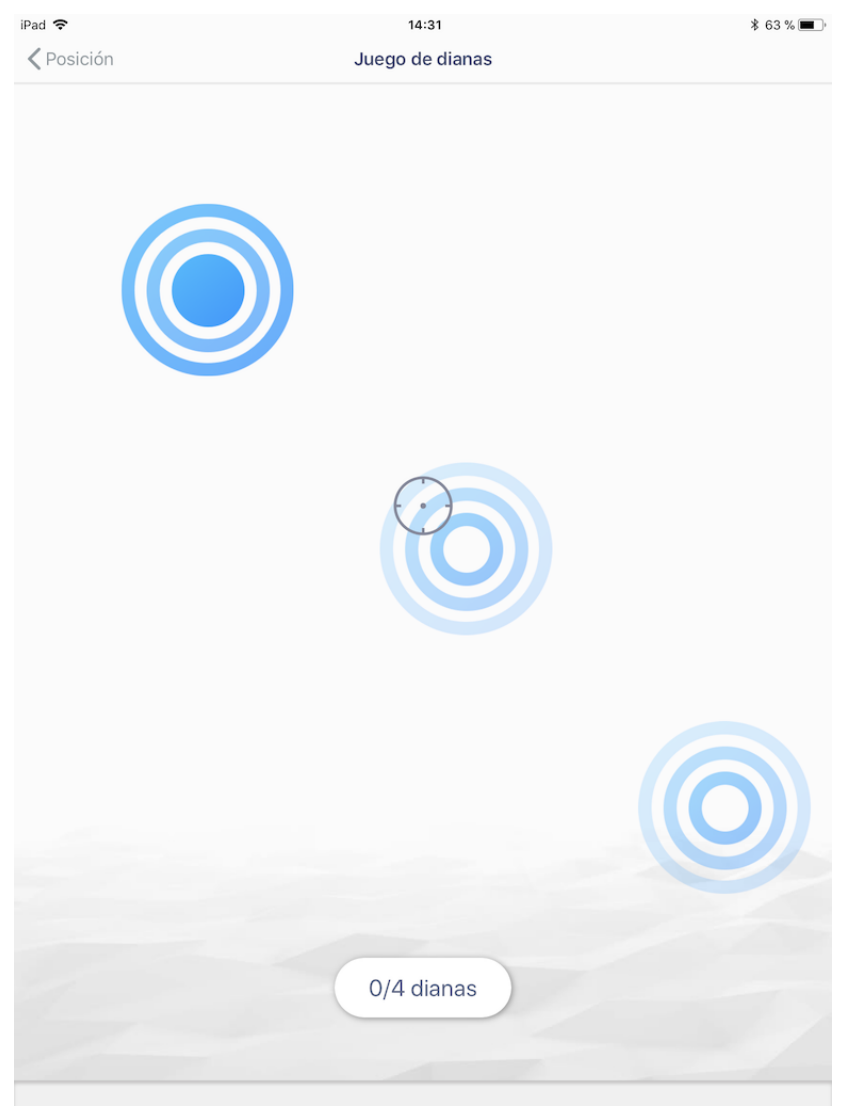

(a)
23:07 Fri21 Jun
$<$ Posición
Juego de dianas

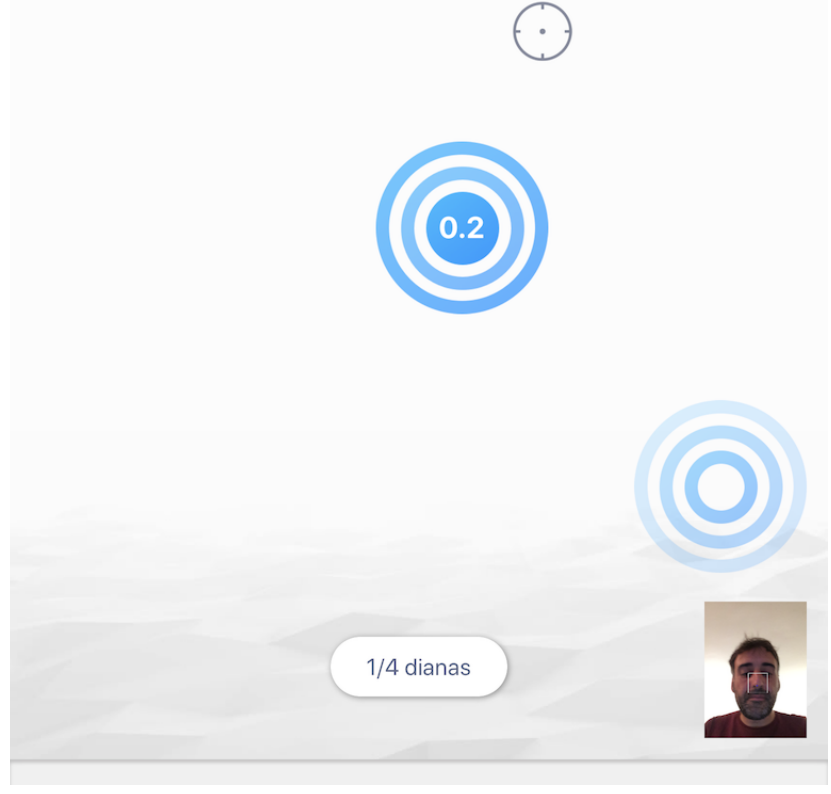

(b)

Figure 8. Screenshots of the dart game with two dwell-time criterion: (a) 0-ms dwell-time criterion: the target was selected immediately when the center of the cursor entered inside the target, and (b) 200-ms dwell-time criterion.

The application started with a login form, which was used to determine the patient profile. According to the profile that was established, the application showed different target patterns covering the desired range of motion of the profile (following either horizontal, vertical, diagonal or random paths). The user got a visual feedback of its motion through the movement of a cursor displayed in the dart game.

To measure the real-time neck mobility performed by subjects while using the application, we used wireless ENLAZA inertial sensors (Werium ${ }^{\mathrm{TM}}$ system [40]). Inertial sensors included an accelerometer, a gyroscope and a magnetometer which sensed linear acceleration, the turn rate and an accurate angular monitoring along three reference axis. Inertial sensors are widely used to measure motor activities [41-43]. Specifically, Werium intertial sensors were previously validated for cervical ROM as well as for other joints [44,45]. The sensors are small and lightweight, so they are barely invasive. Their use would allow to record full ROM, as we previously stated that the application itself was not able monitor full ROM. Two sensors were placed on the subject to conduct the real-time measurement, following the location protocol given by the manufacturer. Sensor 1 was placed on the forehead of the subject, fixed with an elastic band (see Figure 9a,c). Sensor 2 was placed on T1-T2 thoracic vertebrae, fixed with double sided fixing tape (see Figure 9b,c).

\subsubsection{Procedure}

The study was conducted according to the guidelines of the Declaration of Helsinki and approved by the Research Ethics Committee of the University of the Balearic Islands (Exp.174CER20). Each experiment was conducted by a collaborator of the research team, with previous training on the procedure. The experiment consisted in performing several games/matches with the exergame, corresponding to different levels of demand of ROM. 
Informed consent was obtained from all subjects involved in the study. They were instructed to play the exergame, following the application instructions, holding the device still and moving the cursor by moving their head. Subjects were in an experiment room, seated in a chair with their back supported on the backrest, naturally holding the iPad in front of their head (see Figure 10), with their elbows resting on a height-adjustable treatment table. This position (back on the backrest and elbows resting on the table) was designed to maintain a natural position holding a mobile device while controlling possible compensation movements.

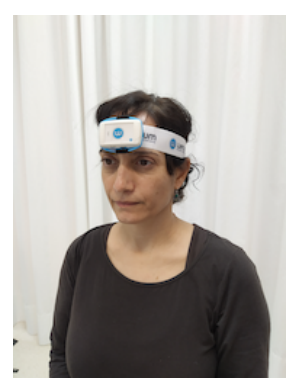

(a)

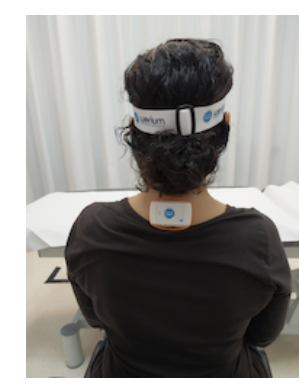

(b)

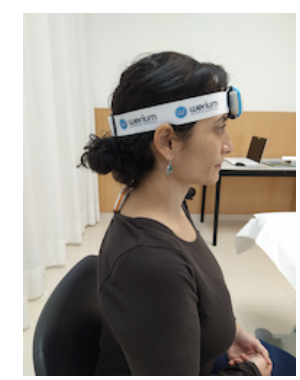

(c)

Figure 9. Placement of the inertial sensors: (a) sensor 1 (b) sensor 2 (c) sensor 1 and sensor 2.

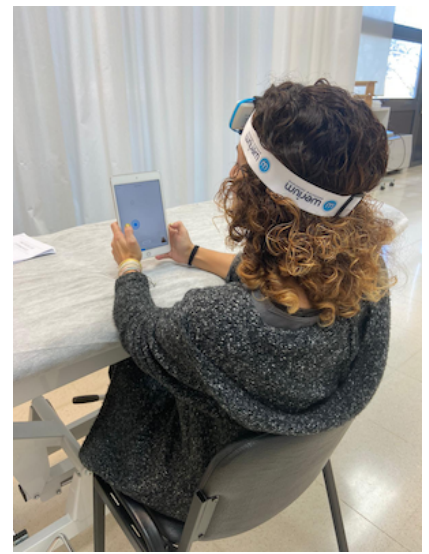

(a)

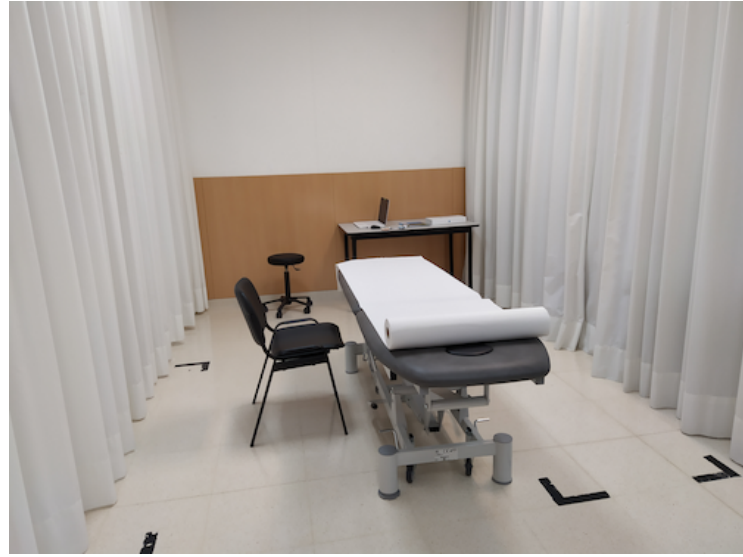

(b)

Figure 10. (a) Subject of the experiment playing the exergame in (b) the experiment room.

After sensors were placed, subjects were asked to play the exergame, and to select targets as quickly and accurately as possible. Every subject was asked to play a match with the exergame set for each profile. They were allowed to rest as needed between profiles. Movement in every direction was real-time recorded via the inertial sensors and Werium software. Any incident observed or informed by the subjects was recorded by the collaborator. Testing lasted about 30 min per participant.

The total number of sessions was 24 participants $\times 4$ profiles $=96$. During every session, the ROM of the subjects reported by the sensors (flexion, extension, lateral flexion, rotation) were recorded.

\section{Results and Discussion}

In this section, results for each preset profile are given for all the movement directions of the cervical area: flexion, extension, right lateral flexion, left lateral flexion, right rotation, left rotation.

Outliers were removed using the Interquartile Range (IQR) method.

Results showed that recorded mobility was below the 80th percentile of the established maximum at all movements and profiles. Even the maximum movement measured stayed within limits in almost every movement and profile, except for extension. Extension 
movements in profiles 1 and 2 (see Tables 3 and 4) showed that the maximum recorded exceeded significantly the preset limits at least once. One possible explanation, from the observation and data, suggested that the maximum of extension recorded may be due to moments in which the head-tracker reference was lost, and the manoeuvre done by the subject to recover the nose tracking was doing a movement out of range of the frontface camera and back, that could be an extension movement. Nevertheless, extension movement was within limits at 80th percentile for these profiles. For profiles 3 and 4 (see Tables 5 and 6), the mobile application would not be able to exceed the limits of ROM preset due to the head-tracker limits that were determined in the first experiment.

Table 3. ROM results of Profile 1 (After outlier filtering, the analyzed data for the Profile 1 supposed a $98 \%$ of the total flexion-extension raw data, a $96 \%$ of the total lateral flexion raw data, and a $99 \%$ of the total rotation raw data). The cases where the maximum ROM of the subjects reported by the ENLAZA inertial sensors exceeded the preset ROM defined for the profile are marked with an asterisk.

\begin{tabular}{cccccc}
\hline Movement & Mean & Standard Deviation & Maximum & 80th Percentile & Preset ROM \\
\hline Flexion & $4.39^{\circ}$ & $3.40^{\circ}$ & $19.17^{\circ}$ & $6.91^{\circ}$ & $20^{\circ}$ \\
Extension & $8.15^{\circ}$ & $5.97^{\circ}$ & $26.16^{\circ}$ & $13.15^{\circ}$ & $15^{\circ}$ \\
Right lateral flexion & $2.00^{\circ}$ & $1.62^{\circ}$ & $6.51^{\circ}$ & $3.32^{\circ}$ & $5^{\circ}$ \\
Left lateral flexion & $1.45^{\circ}$ & $1.09^{\circ}$ & $5.49^{\circ}$ & $2.30^{\circ}$ & $5^{\circ}$ \\
Right rotation & $7.03^{\circ}$ & $5.43^{\circ}$ & $23.41^{\circ}$ & $11.60^{\circ}$ & $25^{\circ}$ \\
Left rotation & $5.71^{\circ}$ & $4.21^{\circ}$ & $21.51^{\circ}$ & $9.34^{\circ}$ & $25^{\circ}$ \\
\hline
\end{tabular}

Table 4. ROM results of Profile 2 (After outlier filtering, the analyzed data for the Profile 2 supposed a $98 \%$ of the total flexion-extension raw data, a $97 \%$ of the total lateral flexion raw data, and a $98 \%$ of the total rotation raw data). The cases where the maximum ROM of the subjects reported by the ENLAZA inertial sensors exceeded the preset ROM defined for the profile are marked with an asterisk.

\begin{tabular}{cccccc}
\hline Movement & Mean & Standard Deviation & Maximum & 80th Percentile & Preset ROM \\
\hline Flexion & $9.18^{\circ}$ & $6.84^{\circ}$ & $30.98^{\circ} *$ & $14.46^{\circ}$ & $30^{\circ}$ \\
Extension & $7.74^{\circ}$ & $5.77^{\circ}$ & $26.75^{\circ}$ & $12.70^{\circ}$ & $20^{\circ}$ \\
Right lateral flexion & $2.13^{\circ}$ & $1.55^{\circ}$ & $7.10^{\circ}$ & $3.33^{\circ}$ & $35^{\circ}$ \\
Left lateral flexion & $1.78^{\circ}$ & $1.39^{\circ}$ & $6.29^{\circ}$ & $2.85^{\circ}$ & $35^{\circ}$ \\
Right rotation & $6.50^{\circ}$ & $4.92^{\circ}$ & $21.51^{\circ}$ & $10.83^{\circ}$ & $8.79^{\circ}$ \\
Left rotation & $5.48^{\circ}$ & $4.24^{\circ}$ & $20.00^{\circ}$ & $40^{\circ}$ \\
\hline
\end{tabular}

Table 5. ROM results of Profile 3 (After outliers' filtering, the analyzed data for the Profile 3 supposed a $98 \%$ of the total flexion-extension raw data, a $93 \%$ of the total lateral flexion raw data, and a $99 \%$ of the total rotation raw data).

\begin{tabular}{cccccc}
\hline Movement & Mean & Standard Deviation & Maximum & 80th Percentile & Preset ROM \\
\hline Flexion & $10.16^{\circ}$ & $7.87^{\circ}$ & $33.37^{\circ}$ & $16.96^{\circ}$ & $40^{\circ}$ \\
Extension & $9.01^{\circ}$ & $7.02^{\circ}$ & $30.22^{\circ}$ & $14.78^{\circ}$ & $40^{\circ}$ \\
Right lateral flexion & $2.11^{\circ}$ & $1.81^{\circ}$ & $7.30^{\circ}$ & $3.65^{\circ}$ & $45^{\circ}$ \\
Left lateral flexion & $2.31^{\circ}$ & $1.74^{\circ}$ & $8.00^{\circ}$ & $3.61^{\circ}$ & $45^{\circ}$ \\
Right rotation & $9.00^{\circ}$ & $6.48^{\circ}$ & $29.51^{\circ}$ & $14.67^{\circ}$ & $70^{\circ}$ \\
Left rotation & $6.10^{\circ}$ & $4.96^{\circ}$ & $21.67^{\circ}$ & $10.00^{\circ}$ & $70^{\circ}$ \\
\hline
\end{tabular}


Table 6. ROM results of Profile 4 (After outliers' filtering, the analyzed data for the Profile 4 supposed a $99 \%$ of the total flexion-extension raw data, a $96 \%$ of the total lateral flexion raw data, and a $98 \%$ of the total rotation raw data).

\begin{tabular}{cccccc}
\hline Movement & Mean & Standard Deviation & Maximum & 80th Percentile & Preset ROM \\
\hline Flexion & $7.05^{\circ}$ & $5.16^{\circ}$ & $24.84^{\circ}$ & $11.47^{\circ}$ & $45^{\circ}$ \\
Extension & $8.70^{\circ}$ & $6.16^{\circ}$ & $29.67^{\circ}$ & $14.12^{\circ}$ & $45^{\circ}$ \\
Right lateral flexion & $1.68^{\circ}$ & $1.27^{\circ}$ & $6.15^{\circ}$ & $2.71^{\circ}$ & $45^{\circ}$ \\
Left lateral flexion & $1.96^{\circ}$ & $1.58^{\circ}$ & $6.20^{\circ}$ & $3.39^{\circ}$ & $45^{\circ}$ \\
Right rotation & $6.40^{\circ}$ & $4.80^{\circ}$ & $22.07^{\circ}$ & $10.37^{\circ}$ & $70^{\circ}$ \\
Left rotation & $6.25^{\circ}$ & $4.67^{\circ}$ & $20.70^{\circ}$ & $10.32^{\circ}$ & $70^{\circ}$ \\
\hline
\end{tabular}

Results not only confirmed safety, in terms of ROM requirements for each profile, according with the safety parameters previously established, but informed also about other aspects. One of these findings was that the mobile application required similar maximum ROM for the different profiles, with differences in flexion: profiles 1, 2 and 3 showed a slightly increase in mobility demand by the mobile application in flexion. Profile 4 (see Table 6), on the other hand, did not show this increasing tendency. Profile 4 was not preset as to continue this increase tendency, but to focus on other rehabilitation parameters. Thus, it was also expected not to detect an increase of ROM demand for this profile. In addition, one unexpected finding was the virtual absence of lateral flexion for the interaction with the mobile application, observed in every profile. Further work is required to clarify whether it is due to the configuration of the targets on the screen (and so, a mobile application performance finding), or whether it is a phenomenon linked to the interaction with mobile devices in general.

All these findings, in addition to the results of the intended evaluation, provided valuable information for future lines of work. Data collected suggested that it would be the combination of different parameters of the mobile application, and not only ROM, what would determine the effectiveness of the exergame as a therapeutic exercise application. In order to work gradually and adapt to the objectives of the rehabilitation and the patient's situation (functional mobility recovery, motor control, strength, etc.), it would be needed to combine parameters as required speed of movement, dwell-time for target selection, number of targets, moment of appearance or disappearance of the targets, etc. If we want to focus on more ROM demand for the medium and advanced profiles (namely profile 3 and 4), it would be necessary to study the feasibility of working with the gain parameter, so the mobile application would demand more ROM for the same movement in screen.

\section{Conclusions}

In this paper, we present a evaluation study of a camera-based head-tracker mobile application for monitoring neck movements for cervical rehabilitation purposes. Due to the use of the camera, this application has the advantage that it does not need any contact sensor and the user can move freely, without any external limitation. The objective of this paper is to present the technical feasibility and a first safety evaluation of the camera-based head-tracker to monitor the neck movements.

First, we explored at what extent the head-tracker was able to monitor the user's neck movements. On that question, the study found that camera-based head-tracker is able to monitor from the $50 \%$ to the $64.5 \%$ of the full cervical range of motion. This result proved that a camera-based head-tracker was a feasible tool for cervical rehabilitation purposes, within a functional mobility range of motion. Secondly, an exploratory validation experiment has determined the safety of the designed head-tracker mobile application. We checked that is possible to use the head-tracker for neck movement detection in an exergame for cervical rehabilitation purposes and, that is safe in terms of the required neck range of motion demanded by the exergame for each preset patient profile. At this point, we can conclude that the camera-based exergame did not require more range of motion than the preset profile user was capable to perform. 
As the objective of this paper was to present the technical feasibility and a first safety study, participants in the presented studies were healthy subjects. In order to continue with the validation of the exergame mobile application using a camera-based head tracker as a sensor, further work needs be conducted, including clinical research studies, with actual patients.

In addition, we point out that this research could serve as a base for future studies on the use of camera-based head-trackers for other healthcare purposes, as we proved that is able to monitor the user's head movements by means of the front-facing camera of a mobile device.

Author Contributions: conceptualization, I.S.-B., K.S.-S.-F. and M.F.R.-M.; methodology, I.S.-B., K.S.-S.-F. and R.M.-S.; software, M.F.R.-M. and R.M.-S.; validation, K.S.-S.-F. and I.S.-B.; formal analysis, I.S.-B., M.F.R.-M. and R.M.-S.; investigation, I.S.-B., K.S.-S.-F. and P.M.-B.; data curation, M.F.R.-M. and R.M.-S.; writing—original draft preparation, I.S.-B., M.F.R.-M. and R.M.-S.; writing—review and editing, I.S.-B., M.F.R.-M., R.M.-S., P.M.-B. and J.V.; supervision, I.S.-B., M.F.R.-M., R.M.-S. and P.M.-B.; project administration, I.S.-B. and J.V. All authors have read and agreed to the published version of the manuscript.

Funding: This research was funded by the Spanish Government with project TIN2016-81143-R (MINECO/AEI/ERDF, EU) and grant number PID2019-104829RA-I00/AEI/10.13039/501100011033.

Institutional Review Board Statement: The study was conducted according to the guidelines of the Declaration of Helsinki and approved by the Research Ethics Committee of the University of the Balearic Islands (Exp.174CER20).

Informed Consent Statement: Informed consent was obtained from all subjects involved in the study.

Data Availability Statement: The data presented in this study are available on request from the corresponding author. The data are not publicly available due to data privacy restrictions.

Acknowledgments: The authors acknowledge the Ministerio de Economía, Industria y Competitividad (MINECO), the Agencia Estatal de Investigacion (AEI), and the European Regional Development Funds (ERDF) for their support to the project TIN2016-81143-R (MINECO/AEI/ERDF, EU) and the Spanish Government for its support by the Project EXPLainable Artificial INtelligence systems for health and well-beING (EXPLAINING) (PID2019-104829RA-I00/AEI/10.13039/501100011033). We also thank the University of the Balearic Islands, the Department of Nursing and Physiotherapy, and the Department of Mathematics and Computer Science for their support.

Conflicts of Interest: The authors declare no conflict of interest. The funders had no role in the design of the study; in the collection, analyses, or interpretation of data; in the writing of the manuscript, or in the decision to publish the results.

\section{References}

1. Mauri, C.; Granollers i Saltiveri, T.; Lorés Vidal, J.; García, M. Computer vision interaction for people with severe movement restrictions. Hum. Technol. Interdiscip. J. Humans ICT Environ. 2006, 2, 38-54. [CrossRef]

2. Manresa-Yee, C.; Ponsa, P.; Salinas, I.; Perales, F.J.; Negre, F.; Varona, J. Observing the use of an input device for rehabilitation purposes. Behav. Inf. Technol. 2014, 33, 271-282. [CrossRef]

3. Cohen, S.P. Epidemiology, diagnosis, and treatment of neck pain. Mayo Clin. Proc. 2015, 90. [CrossRef]

4. Hoy, D.; March, L.; Woolf, A.; Blyth, F.; Brooks, P.; Smith, E.; Vos, T.; Jan, B.; Blore, J.; Murray, C.; Burstein, R.; Buchbinder, R. The global burden of neck pain: Estimates from the global burden of disease 2010 study. Ann. Rheum. Dis. 2014, 73, 1309-1315. [CrossRef] [PubMed]

5. Yamato, T.P.; Saragiotto, B.T.; Maher, C. Therapeutic exercise for chronic non-specific neck pain: PEDro systematic review update. Br. J. Sport. Med. 2015, 49, 1350. [CrossRef]

6. Salo, P.; Ylönen-Käyrä, N.; Häkkinen, A.; Kautiainen, H.; Mälkiä, E.; Ylinen, J. Effects of long-term home-based exercise on health-related quality of life in patients with chronic neck pain: A randomized study with a 1-year follow-up. Disabil. Rehabil. 2012, 34, 1971-1977. [CrossRef] [PubMed]

7. Cheng, C.H.; Su, H.T.; Yen, L.W.; Liu, W.Y.; Cheng, H.Y.K. Long-term effects of therapeutic exercise on nonspecific chronic neck pain: A literature review. J. Phys. Ther. Sci. 2015, 27, 1271-1276. [CrossRef]

8. McCaskey, M.A.; Schuster-Amft, C.; Wirth, B.; Suica, Z.; De Bruin, E.D. Effects of proprioceptive exercises on pain and function in chronic neck and low back pain rehabilitation: A systematic literature review. BMC Musculoskelet. Disord. 2014, 15, 382. [CrossRef] [PubMed] 
9. Zronek, M.; Sanker, H.; Newcomb, J.; Donaldson, M. The influence of home exercise programs for patients with non-specific or specific neck pain: A systematic review of the literature. J. Man. Manip. Ther. (Maney Publ.) 2016, 24, 62-73. [CrossRef] [PubMed]

10. Jaume-i Capó, A.; Martínez-Bueso, P.; Moyà-Alcover, B.; Varona, J. Improving vision-based motor rehabilitation interactive systems for users with disabilities using mirror feedback. Sci. World J. 2014, 2014, 964576. [CrossRef]

11. Adlakha, S.; Chhabra, D.; Shukla, P. Effectiveness of gamification for the rehabilitation of neurodegenerative disorders. Chaos Solitons Fractals 2020, 140. [CrossRef]

12. Vugts, M.; Zedlitz, A.; Joosen, M.; Vrijhoef, H. Serious gaming during multidisciplinary rehabilitation for patients with chronic pain or fatigue symptoms: Mixed methods design of a realist process evaluation. J. Med. Internet Res. $2020,22$. [CrossRef] [PubMed]

13. Collado-Mateo, D.; Merellano-Navarro, E.; Olivares, P.R.; García-Rubio, J.; Gusi, N. Effect of exergames on musculoskeletal pain: A systematic review and meta-analysis. Scand. J. Med. Sci. Sport. 2018, 28, 760-771. [CrossRef] [PubMed]

14. Garcia-Agundez, A.; Folkerts, A.K.; Konrad, R.; Caserman, P.; Tregel, T.; Goosses, M.; Göbel, S.; Kalbe, E. Recent advances in rehabilitation for Parkinson's Disease with Exergames: A Systematic Review. J. Neuroeng. Rehabil. 2019, 16, 1-17. [CrossRef]

15. Bonnechère, B.; Jansen, B.; Omelina, L.; Van Sint Jan, S. The use of commercial video games in rehabilitation: A systematic review. Int. J. Rehabil. Res. 2016, 39, 277-290. [CrossRef] [PubMed]

16. Baranyi, R.; Czech, P.; Hofstatter, S.; Aigner, C.; Grechenig, T. Analysis, Design, and Prototypical Implementation of a Serious Game Reha@Stroke to Support Rehabilitation of Stroke Patients with the Help of a Mobile Phone. IEEE Trans. Games 2020, 12, 341-350. [CrossRef]

17. De Oliveira, L.; Lamounier, E.; Andrade, A.; Lopes, R.; Da Costa, S.; De Oliveira, I.; Carneiro, J.; Daibert, P.; Cardoso, A. Application of Serious Games based on Virtual Reality for Rehabilitation of Patients with Parkinson's Disease through a Wrist Orthosis I Aplicacao de Jogos Serio baseado em Realidade Virtual para Reabilitacao de Pacientes com Doenca de Parkinson por meio. In Proceedings of the 2020 22nd Symposium on Virtual and Augmented Reality, SVR 2020, Porto de Galinhas, Brazil, 7-10 November 2020; pp. 306-312. [CrossRef]

18. Norouzi-Gheidari, N.; Hernandez, A.; Archambault, P.; Higgins, J.; Poissant, L.; Kairy, D. Feasibility, safety and efficacy of a virtual reality exergame system to supplement upper extremity rehabilitation post-stroke: A pilot randomized clinical trial and proof of principle. Int. J. Environ. Res. Public Health 2020, 17, 113. [CrossRef]

19. Meijer, H.; Graafland, M.; Goslings, J.; Schijven, M. Systematic Review on the Effects of Serious Games and Wearable Technology Used in Rehabilitation of Patients With Traumatic Bone and Soft Tissue Injuries. Arch. Phys. Med. Rehabil. 2018, 99, 1890-1899. [CrossRef]

20. Rechy-Ramirez, E.; Marin-Hernandez, A.; Rios-Figueroa, H. A human-computer interface for wrist rehabilitation: A pilot study using commercial sensors to detect wrist movements. Vis. Comput. 2019, 35, 41-55. [CrossRef]

21. Noor, C.; Khairunizam, W.; Syarifah, S.; Zunaidi, I.; Ling, L.; Shahriman, A.; Zuradzman, M.; Mustafa, W. Arm Games for Virtual Reality Based Post-Stroke Rehabilitation; Springer International Publishing: Cham, Switzerland 2020; pp. 91-101._10. [CrossRef]

22. Baranyi, R.; Czech, P.; Walcher, F.; Aigner, C.; Grechenig, T. Reha@Stroke-A Mobile Application to Support People Suffering from a Stroke Through Their Rehabilitation. In Proceedings of the 2019 IEEE 7th International Conference on Serious Games and Applications for Health, SeGAH 2019, Kyoto, Japan, 5-7 August 2019; doi:10.1109/SeGAH.2019.8882447. [CrossRef]

23. Mihajlovic, Z.; Popovic, S.; Brkic, K.; Cosic, K. A system for head-neck rehabilitation exercises based on serious gaming and virtual reality. Multimed. Tools Appl. 2018, 77, 19113-19137. [CrossRef]

24. Lawanont, W.; Inoue, M.; Mongkolnam, P.; Nukoolkit, C. Neck posture monitoring system based on image detection and smartphone sensors using the prolonged usage classification concept. IEEJ Trans. Electr. Electron. Eng. 2018, 13, 1501-1510. [CrossRef]

25. Lawanont, W.; Mongkolnam, P.; Nukoolkit, C. Smartphone posture monitoring system to prevent unhealthy neck postures. In Proceedings of the IEEE 2015 12th International Joint Conference on Computer Science and Software Engineering, JCSSE 2015, Prague, Czech Republic, 22-24 July 2015; pp. 331-336. [CrossRef]

26. Roig-Maimó, M.F.; Manresa-Yee, C.; Varona, J. A Robust Camera-Based Interface for Mobile Entertainment. Sensors 2016, 16, 254. [CrossRef] [PubMed]

27. Roig-Maimó, M.F.; MacKenzie, I.S.; Manresa-Yee, C.; Varona, J. Head-tracking interfaces on mobile devices: Evaluation using Fitts' law and a new multi-directional corner task for small displays. Int. J. Hum.-Comput. Stud. 2018, 112, 1-15. [CrossRef]

28. Roig-Maimó, M.F.; Manresa-Yee, C.; Varona, J.; MacKenzie, I.S. Evaluation of a Mobile Head-Tracker Interface for Accessibility. In Computers Helping People with Special Needs; Miesenberger, K., Bühler, C., Penaz, P., Eds.; Springer International Publishing: Cham, Switzerland, 2016; pp. 449-456.

29. Hislop, H.; Avers, D.; Brown, M.D. Daniels and Worthingham's Muscle Testing: Techniques of Manual Examination; Elsevier: Amsterdam, The Netherlands, 2013.

30. Cobian, D.G.; Daehn, N.S.; Anderson, P.A.; Heiderscheit, B.C. Active cervical and lumbar range of motion during performance of activities of daily living in healthy young adults. Spine 2013, 38, 1754-1763. [CrossRef] [PubMed]

31. Bible, J.E.; Biswas, D.; Miller, C.P.; Whang, P.G.; Grauer, J.N. Normal functional range of motion of the cervical spine during 15 activities of daily living. J. Spinal Disord. Tech. 2010, 23, 15-21. [CrossRef]

32. Dufour, M.; Pillu, M. Biomecánica Funcional. Miembros, Cabeza, Tronco; Elsevier: Amsterdam, The Netherlands, 2018.

33. De Waele, W.G.C.; Vidal, P. Biomechanics, Movement Strategies and the Evolution of the Head-Neck System in. Inf. Process. Underlying Gaze Control 2018, 12, 415. 
34. ISO 9241-11:2018 Ergonomics of Human-System Interaction-Part 11: Usability: Definitions and Concepts. Available online: https://www.iso.org/obp/ui/\#iso:std:iso:9241:-11:ed-2:v1:en (accessed on 11 December 2020).

35. Farooq, M.N.; Bandpei, M.A.M.; Ali, M.; Khan, G.A. Reliability of the universal goniometer for assessing active cervical range of motion in asymptomatic healthy persons. Pak. J. Med Sci. 2016, 32, 457. [CrossRef]

36. Jones, A.; Sealey, R.; Crowe, M.; Gordon, S. Concurrent validity and reliability of the Simple Goniometer iPhone app compared with the Universal Goniometer. Physiother. Theory Pract. 2014, 30, 512-516. [CrossRef]

37. Milani, P.; Coccetta, C.A.; Rabini, A.; Sciarra, T.; Massazza, G.; Ferriero, G. Mobile smartphone applications for body position measurement in rehabilitation: A review of goniometric tools. PMER 2014, 6, 1038-1043.

38. Farooq, M.N.; Mohseni-Bandpei, M.A.; Gilani, S.A.; Ashfaq, M.; Mahmood, Q. The effects of neck mobilization in patients with chronic neck pain: A randomized controlled trial. J. Bodyw. Mov. Ther. 2018, 22, 24-31. [CrossRef]

39. Kasch, H.; Stengaard-Pedersen, K.; Arendt-Nielsen, L.; Staehelin Jensen, T. Headache, neck pain, and neck mobility after acute whiplash injury: A prospective study. Spine 2001, 26, 1246-1251. [CrossRef] [PubMed]

40. Werium Assistive Solutions S.L. Available online: https://www.weriumsolutions.com/ (accessed on 11 December 2020).

41. Pollind, M.; Soangra, R. Development and Validation of Wearable Inertial Sensor System for Postural Sway Analysis. Measurement 2020, 165, 108101. [CrossRef]

42. Santospagnuolo, A.; Bruno, A.; Pagnoni, A.; Martello, F.; Santoboni, F.; Perroni, F.; Vulpiani, M.; Vetrano, M. Validity and Reliability of GYKO Inertial Sensor System for the Assessment of ROM of Elbow. J. Sports Med. Phys. Fitness. 2019, 59, 1466-1471 [CrossRef] [PubMed]

43. Liu, K.; Yan, J.; Liu, Y.; Ye, M. Noninvasive Estimation of Joint Moments with Inertial Sensor System for Analysis of STS Rehabilitation Training. J. Healthc. Eng. 2018, 2018, 6570617. [CrossRef] [PubMed]

44. Velasco, M.A.; Raya, R.; Muzzioli, L.; Morelli, D.; Otero, A.; Iosa, M.; Cincotti, F.; Rocon, E. Evaluation of cervical posture improvement of children with cerebral palsy after physical therapy based on head movements and serious games. Biomed. Eng. Online 2017, 16, 1-13. [CrossRef] [PubMed]

45. Vergara-Diaz, G.; O’Brien, A.; Adans-Dester, C.; Raya, R.; Velasco, M.; Dominguez-Iglesia, M.; Bonzi, L.; Rocon, E.; Bonato, P. Cervical Posture Therapy Using a Head-Based Computer Interface in Children With Cerebral Palsy. Arch. Phys. Med. Rehabil. 2017, 98, e40. [CrossRef] 